\title{
Telehealth: Achieving Older Adult Access to Primary Healthcare in New Zealand
} Arun Sam Singh Selwyn Jebaraj

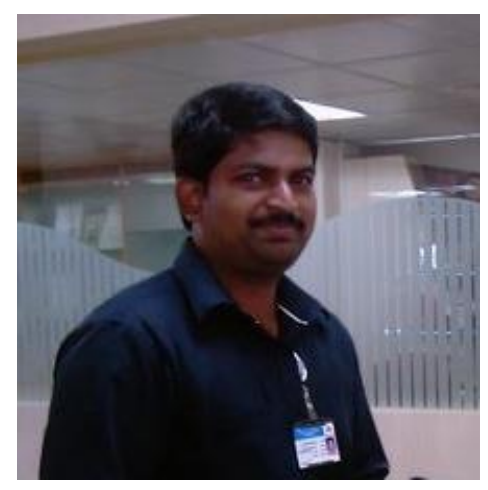

Multiple factors are combining to support a strong primary care system that is essential to correct health inequalities and improve the health of New Zealanders.

- Health and disability expenditures to older people contribute a higher amount than any other age group in New Zealand.

- With a growing aged population, timely receipt of healthcare has shown a difference in health outcomes.

- The number of adults accessing the internet is increasing, and they have a positive attitude towards telehealth services.

- Telehealth application can reduce the cost and improve the accessibility to older adults making it possible to stay in their home.

- Telemedicine supports primary care clinicians to care more patients.

Application of telehealth services will benefit people of New Zealand, but an extensive application into primary care needs to overcome challenges such as accepted strategies, better clinician support, appropriate resources, and a suitable infrastructure investment. What follows is a timely review of the health needs of New Zealanders and the potential for telehealth to meet this growing challenge.

\section{An Increasingly Aged Population}

The ageing population in New Zealand is a major contributor to a demographic shift that 
demands well considered changes in public policy. ${ }^{1}$ Similar to other developed countries, New Zealand's ageing population is increasing and is expected to reach $21 \%$ by 2031 (Figure 1).

Older adults tend to visit primary care providers more frequently and pay a huge cost compared to other age groups. ${ }^{2}$ Income for older adults is uncertain, particularly for Māori (the indigenous people of New Zealand) over the age of 65 years. ${ }^{3}$ As most of these older adults have low, fixed income, they are burdened with the need to spend more money for primary care. ${ }^{3}$

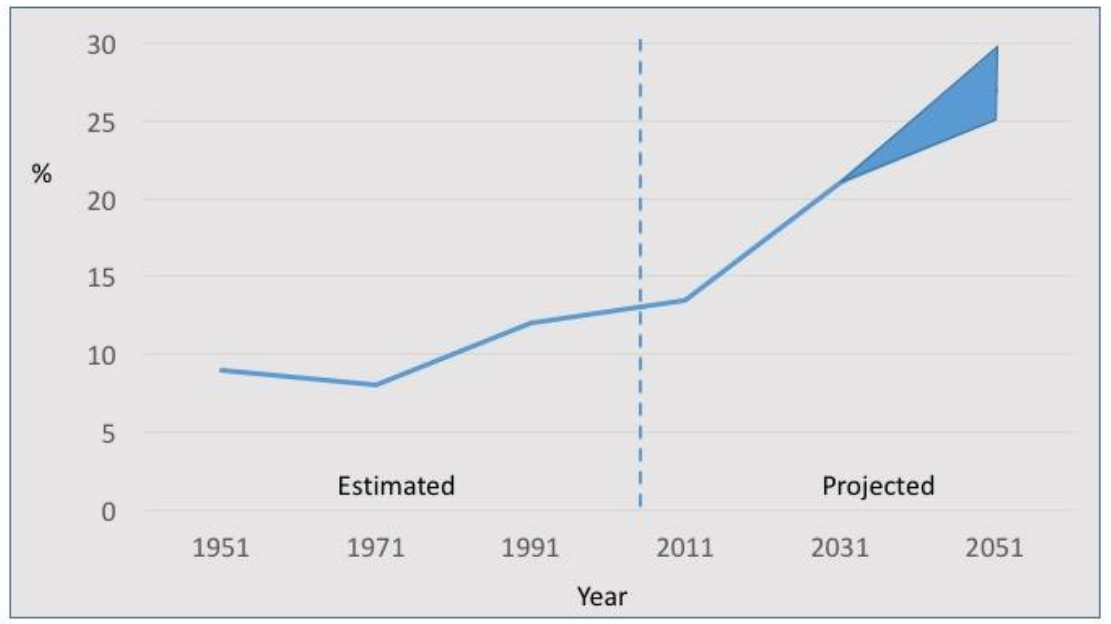

Figure 1. Proportion of New Zealand population older than 65 years. ${ }^{4}$

Studies report that delayed primary care access results in a decline in health status, and prolonged hospitalization, which contribute to expensive hospital treatment. ${ }^{5}$ When primary care service is not easily accessible, older adults tend to visit the emergency department and get hospitalized. Frequent hospitalization is associated with rapid deterioration in function and loss of the ability for independent living, which puts these older patients at risk of permanent admission to long-term care facilities. Fortunately, timely access to primary care can create a positive difference in health outcomes.

Older adults in New Zealand are required to be enrolled with a primary care provider to 
access care. However, there is a possibility of patients going directly to hospital emergency departments, which offer free access rather than paying a lower GP (general practitioner) consultation fee. Even those who are enrolled may not visit primary care because of the expense and may seek care in-hospital emergency departments.

This delay in primary care can cause less financial cost when treated by a primary care provider compared to the same treatment in the emergency department, which is publically funded. ${ }^{9}$ Thus, in a publicly funded healthcare system these "preventable" hospitalizations may add additional cost. ${ }^{9,10}$ Barbara Stewart, a member of New Zealand Parliament, stated that preventing $1 \%$ of hospital admission would bring a huge financial saving to the New Zealand health service. ${ }^{11}$

\section{Options to Improve Primary Care Access: The U.S. and UK Experience}

Patient-centered medical care in the United States is delivered by teams, headed by a primary care physician. ${ }^{12}$ This model helps improve primary care access and quality of life, and reduces the associated costs of long-term healthcare. ${ }^{13,14}$ The collaborative care model for older adult mental health in the U. S. established as a result of more than 70 randomized controlled trials. ${ }^{15-17}$ integrates physical and mental healthcare in Medicaid health homes and saves healthcare cost. ${ }^{18}$ There was a substantial improvement for about $20 \%$ of patients who started medication in a primary care setup. ${ }^{19-21}$

In the United Kingdom, General practice with a telephone triage system uses the system of accessing GP consultation using the telephone. ${ }^{22,23}$ Practice with a telephone triage system reports $27 \%$ of patients are less likely to attend an emergency department. ${ }^{24}$ Pharmacy led care in the UK could fill certain roles in reducing GP visits, with people self-managing their medication. ${ }^{24}$ This can bring down the healthcare cost for long-term conditions and could lead to a reduction in hospital admissions by effectively using the pharmacist-led care. ${ }^{25}$ 
In the UK, individuals take care of their health and wellbeing through self-management, by increasing access to health information, managing a chronic condition, and working efficiently with health and community resources. ${ }^{26-27}$ Studies reveal that self-care programs lead to better disease control, health outcomes, and reduced use of healthcare resources-particular emergency admissions. ${ }^{28}$ The whole system demonstrator program in the UK showed that telehealth has reduced $20 \%$ of emergency admission and mortality by $45 \% .{ }^{29}$ Studies have shown older adults are adapt the technology ${ }^{28}$ and satisfy the vital element of acceptance by older adults. ${ }^{30,31}$ Telehealth

benefits older adults who have difficulty in accessing primary care, ${ }^{32}$ and helps them stay in their home, which has a positive impact on their quality of life and improves chronic care. ${ }^{33-36}$

\section{Telehealth Application in New Zealand}

Older adults who use the internet have a positive attitude towards telehealth services and $61 \%$ of people above 65 used the internet in $2014 .{ }^{34,37}$ New Zealand's use of Information technology in healthcare has become among the highest in the world, especially among primary care providers. ${ }^{38}$ National Telehealth Services receives more than 2 million calls annually, offering the potential for future video calls. ${ }^{39}$ While telehealth can reduce cost and improve the healthcare accessibility, the wider application should overcome the challenges discussed below.

\section{Key Stakeholder Alignment and Shared Awareness in Telehealth Investment}

Providers of telehealth are funded by a national health information technology board, which lacks strong funding for application of telehealth technology. ${ }^{40}$ District Health Boards (DHBs) use telehealth to promote their current service efficiently, rather than reshaping the current way of providing patient care ${ }^{41}$ For an effective wider application, investment should be made by evaluating both healthcare and financial benefits, rather than a motivated thinking. ${ }^{41}$ This involves the need for stakeholder agreement and awareness to incorporate all available resources into telehealth development.

\section{Clinician Adoption of Telehealth Applications}


A gap exists between clinicians willing to use and those who actually use telehealth services. Acceptance will be slow if this use is not made compulsory through policy, supported by strong senior management leadership, and a change in commitment at a clinical level. ${ }^{42}$ Though individual clinicians express interest in accepting the applications, resistance comes from adapting the proper alignment of technologies that lack nationally agreed approaches. ${ }^{41}$

\section{Integrating a New Practice}

Integrating telehealth into an established practice requires continuous technical support. This includes the use of simpler methods, like continuous online training programs, to train and educate the providers of telehealth. To work effectively, the New Zealand Telehealth Board and Telehealth Forum should provide standard guidelines and continuing medical education, along with best practices in telehealth. Change management should be active during the initial stages of implementation. Ultimately, a complete training program is the key to the success of telehealth implementation at all local and national levels. ${ }^{43}$

\section{Operational Business Model for Telehealth}

The anticipated health outcomes of telehealth services can be developed by providing a clear and open partnership between healthcare providers and technology vendors. It is important to develop a cost-effective growth business model that can be sustained in its wider application and generate operational excellence by involving healthcare providers in making use of the technology. 44

\section{Compatibility and Standards}

Currently, there are no protocols to oversee the use of telehealth in an organization. ${ }^{41}$ Good sound quality and a clear picture are an integral part of telehealth application. ${ }^{45}$ Considering that 18 out of $20 \mathrm{DHBs}$ face difficulty in video conferencing interconnectivity across networks, most of the DHBs and Primary Health Organizations (PHOs) ${ }^{40,41}$ are not sure if their video conferencing meets the current HISO 10049.1 video conferencing and interoperating standards (the published standard for videoconferencing 
interoperability). ${ }^{46}$

\section{Legal and Ethical Issues}

New Zealand health professionals are very cautious as the Medical Council of New Zealand provides clear advice on using telehealth and the associated risk in providing medical guidance when physical examination of patients is not practical. Moreover, practicing healthcare professionals "must consider issues of privacy, security and the sensitivity of health information" and stay within the guidelines of the Privacy Code 1994 that states "the health sector must ensure the protection of individual privacy". ${ }^{47}$

\section{Conclusions}

The increasing ageing population and access to primary health is forcing telehealth to expand its operations in order to meet the following goals for telemedicine in New Zealand. These include development or modification of clinical governance and oversight, user friendly platforms, telehealth standards, investment in infrastructure, and awareness of the benefit of telehealth technology. No less important is the need to engage clinicians in the development and use of protocols (Table 1).

Table 1. Goals for telemedicine success in New Zealand

\begin{tabular}{|c|c|}
\hline Goal & Procedures and Outcome \\
\hline $\begin{array}{l}\text { Develop clinical governance that } \\
\text { outlines the direction for national } \\
\text { telehealth applications for older adults }\end{array}$ & $\begin{array}{l}\text { - Examine current program(s) } \\
\text { - Outline future program(s) to increase } \\
\text { telehealth success } \\
\text { - Streamline clinical and technical } \\
\text { decision making }\end{array}$ \\
\hline $\begin{array}{l}\text { Frame an appropriate health } \\
\text { information exchange platform }\end{array}$ & $\begin{array}{l}\text { - Provide continuity of care by sharing } \\
\text { patient information } \\
\text { - Follow accepted interoperable } \\
\text { standards, regardless of where/how } \\
\text { care is provided }\end{array}$ \\
\hline
\end{tabular}




\begin{tabular}{|c|c|}
\hline $\begin{array}{l}\text { Develop approved video conferencing } \\
\text { telehealth standards }\end{array}$ & $\begin{array}{l}\text { - Standardize protocols } \\
\text { - Provide quality of care to patients } \\
\text { through video calls }\end{array}$ \\
\hline $\begin{array}{l}\text { Create sustainable funding for } \\
\text { infrastructure investments }\end{array}$ & $\begin{array}{l}\text { - Funding based on assessing the need } \\
\text { to implement telehealth solutions into } \\
\text { healthcare facilities, short and long } \\
\text { term }\end{array}$ \\
\hline $\begin{array}{l}\text { Create and raise awareness of the } \\
\text { benefit of telehealth technology }\end{array}$ & $\begin{array}{l}\text { - Solutions should be simple and easy } \\
\text { to use } \\
\text { - Incorporate attributes that motivate } \\
\text { older adults to use the technology } \\
\text { - Address points related to resistance to } \\
\text { using the technology }\end{array}$ \\
\hline $\begin{array}{l}\text { Engage clinicians by creating } \\
\text { awareness through training and } \\
\text { education }\end{array}$ & $\begin{array}{l}\text { - Individual clinician training to cover } \\
\text { telehealth policies and protocols } \\
\text { - General computer skills and ongoing } \\
\text { scheduled training to address clinical } \\
\text { and technical support needs }\end{array}$ \\
\hline
\end{tabular}

Sam Selwyn Jebaraj, BPT, MBA Hospital and Health Systems, PG Dip Health Information management, is goal-driven and compassionate, with over 8 years of hands-on experience in hospital management, patient handling, relationship management, project management, resource management, and new business development. Mr. Jebaraj has a record of successfully managing teams across various projects and facility operations, while concurrently providing innovative ideas in new business development. He combines strong communication with organizational and problem solving skills to liaise with various departments, organizations, and the general public to raise awareness and bring support to healthcare facilities. 
Tags:

aging population, chronic condition, community resources, cost, health outcomes, health status, information technology, Medical Council of New Zealand, national health information technology board, New Zealand, New Zealand health service, New Zealand Telehealth Board and Telehealth Forum, patient-centered medical care, primary healthcare, publicly funded healthcare, self-management, telehealth, telemedicine, triage

\section{References}

1. New Zealand Parliment. New Zealand's ageing population 2011 [Available from: https://www.parliament.nz/en/pb/research-papers/document/00PlibCIP031/newzealands-ageing-population.

2. The National Centre of Mental Health Research laWD. Older adults in New Zealand: Population changes, health, service use and workforce needs 2011. URL: http://www.tepou.co.nz/uploads/files/resource-assets/Older-Adults-in-New-ZealandPopulation-Changes-Health-Service-Use-and-Workforce-Needs-September-2011.pdf. Accessed 10/7/16.

3. Frizelle F, King A, Hague K, Ryall T. What are the health policies of the next New Zealand Government? The New Zealand Medical Journal. 2014;127(1401):10-22.

4. Statistics New Zealand. Demographic Aspects of New Zealand's Ageing Population 2006: URL: file:///C:/Users/sowmyaarun/Downloads/demo-as-nz-age-pop\%20(1).pdf.

5. Himmelstein DU, Woolhandler S. Care denied: US residents who are unable to obtain needed medical services. American Journal of Public Health. 1995;85(3):341-4.

6. Stall N, Nowaczynski M, Sinha SK. Back to the future: home-based primary care for older homebound Canadians Part 1: where we are now. Canadian Family Physician. 2013;59(3):237-40.

7. Gold M. Beyond coverage and supply: measuring access to healthcare in today's market. Health Services Research. 1998;33(3 Pt 2):625.

8. Bindman AB, Grumbach K, Osmond D, Komaromy M, Vranizan K, Lurie N, et al. Preventable hospitalizations and access to health care. JAMA. 1995;274(4):305-11.

9. Aday LA, Fleming GV, Andersen R. Access to Medical Care in the US: Who Has It, Who Doesn't. Chicago: Pluribus Press; University of Chicago, Center for Health Administration Studies; 1984. 
10. Short PF, Hahn BA, Beauregard K, Harvey PH, Wilets ML. The effect of universal coverage on health expenditures for the uninsured. Medical Care. 1997;35(2):95-113.

11. New Zealand Parliament. SuperGold Health Check Bill 2013 (Member's Bill Barbara Stewart) 2013 [Available from: https://www.parliament.nz/en/pb/bills-andlaws/bills-digests/document/50PLLaw21781/supergold-health-check-bill-2013members-bill-barbara.

12. Miller WL. Patient-centered medical home $(\mathrm{PCMH})$ recognition: a time for promoting innovation, not measuring standards. The Journal of the American Board of Family Medicine. 2014;27(3):309-11.

13. Donelan K, DesRoches CM, Dittus RS, Buerhaus P. Perspectives of physicians and nurse practitioners on primary care practice. New England Journal of Medicine. 2013;368(20):1898-906.

14. Grumbach K, Bodenheimer T, Grundy P. Outcomes of implementing patient centered medical home interventions. Washington, DC: Patient-Centered Primary Care Collaborative. 2010.

15. Force CPST. Recommendation from the community preventive services task force for use of collaborative care for the management of depressive disorders. American Journal of Preventive Medicine. 2012;42(5):521-4.

16. Gilbody S, Bower P, Fletcher J, et al. Collaborative care for depression: a cumulative meta-analysis and review of longer-term outcomes. Archives of Internal Medicine. 2006;166(21):2314-21.

17. Thota AB, Sipe TA, Byard GJ, et al. Collaborative care to improve the management of depressive disorders: a community guide systematic review and meta-analysis. American Journal of Preventive Medicine. 2012;42(5):525-38.

18. Unützer J, Harbin H, Druss M. The collaborative care model: An approach for integrating physical and mental health care in Medicaid health homes. Center for Health Care Strategies and Mathematica Policy Research, May. 2013.

19. Areán PA, Ayalon L, Hunkeler E, Lin EH, Tang L, Harpole L, et al. Improving depression care for older, minority patients in primary care. Medical Care. 2005;43(4):381-90.

20. Rush AJ, Trivedi M, Carmody TJ, et al. One-year clinical outcomes of depressed public sector outpatients: a benchmark for subsequent studies. Biological Psychiatry. 2004;56(1):46-53.

21. Unützer J, Katon W, Callahan $\mathrm{CM}$, et al. Collaborative care management of late-life depression in the primary care setting: a randomized controlled trial. JAMA. 2002;288(22):2836-45. 
22. Car J, Sheikh A. Telephone consultations. BMJ. 2003;326(7396):966-9.

23. Jiwa M, Mathers N, Campbell M. The effect of GP telephone triage on numbers seeking same-day appointments. Br J Gen Pract. 2002;52(478):390-1.

24. Taylor K, George R, Hammett S. Primary care: today and tomorrow. Improving general practice by working differently. Deloitte Centre for Health Solutions; 2012.

25. Royal Pharmaceutical Society England. Shaping pharmacy for the future: Pharmacist-led care of people with long term conditions. 2014 [Available from: http://www.rpharms.com/policy-pdfs/pharmacist-led-care.pdf.

26. Clark NM, Becker MH, Janz NK, Lorig K, Rakowski W, Anderson L. Selfmanagement of chronic disease by older adults a review and questions for research. Journal of Aging and Health. 1991;3(1):3-27.

27. Coulter A, Ellins J. Effectiveness of strategies for informing, educating, and involving patients. BMJ. 2007;335(7609):24-7.

28. Steiner A, Campbell S, Robison J, Webb D, Roland M. Does PMS improve quality of care. National evaluation of first wave NHS personal medical services pilots Summaries of findings from four research projects London: Department of Health. 2002:11-4.

29. Department of Health. Whole System Demonstrator Programme: Headline Finding 2011 [Available from:

https://www.gov.uk/government/uploads/system/uploads/attachment_data/file/215264/d h_131689.pdf.

30. Hanson J, Percival J, Aldred H, Brownsell S, Hawley M. Attitudes to telecare among older people, professional care workers and informal carers: a preventative strategy or crisis management? Universal Access in the Information Society. 2007;6(2):193-205.

31. Wade R, Cartwright CM, Shaw KA. Factors relating to home telehealth acceptance and usage compliance. Risk management and healthcare policy. Dove Medical Press Limited. Dove Medical Press Limited. 2012;5:25.

32. Gellis ZD, Kenaley B, McGinty J, et al. Outcomes of a telehealth intervention for homebound older adults with heart or chronic respiratory failure: a randomized controlled trial. The Gerontologist. 2012;52(4):541-52.

33. Bashshur RL, Shannon GW, Krupinski EA, et al. National telemedicine initiatives: essential to healthcare reform. Telemedicine and e-Health. 2009;15(6):600-10.

34. Magdalena M, Bujnowska-Fedak M, Grata-Borkowska U. Use of telemedicinebased care for the aging and elderly: promises and pitfalls. Smart Homecare Technology and TeleHealth. Dove Medical Press Limited. 2015;3:91-105. 
35. Tomita MR, M. BJN, Russ LS, Sridhar R. Smart home with healthcare technologies for community-dwelling older adults: Smart Homecare Technology and TeleHealth; 2010. URL: http://www.intechopen.com/books/smart-home-systems/smart-home-withhealthcare-technologies-for-community-dwelling-older-adults. Accessed 10/7/16.

36. Turner KJ, McGee-Lennon M. Advances in telecare over the past ten years. Smart Homecare Technology and TeleHealth. Dove Medical Press Limited. 2013;1(1):21-34.

37. Barry M. SuperSeniors website launched 2015 [Available from: https://www.beehive.govt.nz/release/superseniors-website-launched.

38. Kirk S. Ultrafast broadband 'breaking down geographical barriers' for all rural hospitals 2015 [Available from:

http://www.stuff.co.nz/national/health/73939068/Ultrafast-broadband-breaking-downgeographical-barriers-for-all-rural-hospitals.

39. Stuff. Telehealth revolution means Kiwis can have global health checks from their couch 2016 [Available from: http://www.stuff.co.nz/national/health/76374346/Telehealthrevolution-means-Kiwis-can-have-global-health-checks-from-their-couch.

40. New Zealand Telehealth Forum. New Zealand Telehealth Stocktake of PHO and NGO. NZ Telehealth Forum. 2014 [Available from:

http://healthitboard.health.govt.nz/system/files/documents/pages/new-zealandtelehealth-forum-stocktake-pho-ngo-activity.pdf.

41. Ministry of Health. Stocktake of District Health Boards' Telehealth Activity [Available from: http://healthitboard.health.govt.nz/health-it-groups/new-zealand-telehealthforum/telehealth-resources-and-case-studies/stocktake.

42. Day K, Kerr P. Buller Health Telehealth Pilot: Evaluating an opportunity whose time has come. The University of Aukland. 2010. URL:

https://researchspace.auckland.ac.nz/handle/2292/8297. Accessed 10/7/16.

43. Kerr K, Norris AC. A review of telehealth and its relevance to New Zealand: Karolyn Kerr a thesis presented in partial fulfillment of the requirements of a PhD; 2004.

44. Altharthi MS. Telehealth practice in eight countries: New Zealand, Australia, the USA, Canada, UK, Malaysia, China and India: a thesis presented in partial fulfillment of the requirements of degree of Master in Information Science at Massey University, Albany campus, Auckland, New Zealand: Massey University; 2012.

45. Deloitte. Primary care: Working differently [Available from: http://www2.deloitte.com/content/dam/Deloitte/uk/Documents/life-sciences-healthcare/deloitte-uk-telehealth-telecare.pdf.

46. Ministry of Health. HISO 10049.1 Videoconferencing Interoperability Standard 2014 [Available from:

https://healthitboard.health.govt.nz/system/files/documents/publications/10049- 
1\%20Videoconferencing\%20Interoperability\%20Standard\%20v2\%20\%20April\%202014.pdf.

47. Lucas JAM. Clinicians' perceptions of telemedicine: opportunities and barriers for emergency medicine: University of Aukland. 2013. URL:

https://researchspace.auckland.ac.nz/handle/2292/20430. Accessed 10/7/16 